Tsotetsi, C.T. \& Mile, S.A. Mentor-Mentee Experiences Amidst COVID-19: A Teaching Practice Case Study

\title{
Mentor-Mentee Experiences Amidst COVID-19: A Teaching Practice Case Study
}

\author{
Cias T. Tsotetsi ${ }^{* 1}$ and Selloane A. Mile ${ }^{1}$ \\ *Corresponding Author: tsotetsict@ufs.ac.za \\ 1. University of the Free State, School of Education Studies, South Africa \\ Received : 2021-06-23 \\ Revised : 2021-07-24 \\ Accepted : 2021-08-21 \\ do \\ $10.46303 /$ ressat.2021.12
}

\begin{abstract}
How to cite this paper: Tsotetsi, C.T. \& Mile, S.A. (2021). Mentor-Mentee Experiences Amidst COVID-19: A Teaching Practice Case Study, Research in Social Sciences and Technology. 6(2), 76-95. https://doi.org/10.46303/ressat.2021.12

This is an Open Access article distributed under the terms of the Creative Commons Attribution 4.0 International license (https://creativecommons.org/licenses/by/4.0/).
\end{abstract}

\begin{abstract}
Preparing student teachers for the world of work is seen globally as a challenge. This research aims to explore mentors and mentees experiences in teaching practice during the COVID-19 period. In order to explore the challenge in this study, the following research question guided the paper: What are the teaching practice experiences of mentors and mentees at a school during COVID-19? The research question is a result of limited research done on the experiences of two groups during COVID-19. Informed by the realist social theory, we generated data via telephonic interviews with mentors and mentees in one school. The data was generated through semi-structured Interviews and thematic analysis was a method employed in the analysis of the data. The results present challenges experienced by mentees which, amongst others, include a feeling of inadequacy or a lack of confidence in their abilities to bring about order to the classroom and a feeling of being excluded in meetings and extra-curricular activities. On the other hand, mentors receive mentees without any prior warning or without arrangements made to accommodate them and the absence of the university officials except for assessment. Based on the results, a collaborative approach should be employed to deal with some of the challenges experienced by mentors and mentees.
\end{abstract}

Keywords: Teaching practice; mentees; mentors; COVID-19. 
Tsotetsi, C.T. \& Mile, S.A. Mentor-Mentee Experiences Amidst COVID-19: A Teaching Practice Case Study

\section{Introduction}

Pre-service teaching plays an integral part in teacher training as it provides student teachers with the opportunity to attain real-life work experience (Kiggundu, 2007). While it is the responsibility of institutions of higher learning to provide educational theories and instil them in pre-service teachers, a more significant responsibility lies with practising teachers to provide on-the-job mentorship that will equip necessary skills for pre-service teachers to excel within the teaching profession. Ryan (2016) outlines that pre-service teaching is a time for reflection regarding the student-teacher's field readiness while similarly exploring and negotiating mechanisms to prevail over challenges and encounters that may surface within their teaching occupation.

Simply put, pre-service education means teachers' education before they enter into service. It is also concerned with the significance of learning the methodology of the fundamental qualities to the realisation of becoming a good teacher (Educational Systems Blog, 2013). It has been determined that pre-service teachers divulge concerns in applying learned theories into their actual teaching (Beeth \& Adadan, 2006; Tarman, 2012). Harding and Hbaci (2015) believe that the transition from being full-time students who are supported by university personnel and supervisor teachers to independent teachers (although scaffolded) who are entirely responsible for pedagogical processes and classroom management puts a strain on pre-service teachers. Professional teacher induction programmes provide a wide array of subjects and jargon such as curricula, management, and fairness (Ryan et al., 2017). Several studies have been piloted to scrutinise pre-service teachers' strengths and barriers in pedagogical processes. The glitches are directly associated with their limited experience within the profession, including behavioural management, time management, lack of ability to work with learners with different needs, and the lack of communication skills. The prevailing COVID-19 pandemic conditions further escalated these challenges, forcing schools to revise learner attendance models. Limbers (2020) study outlines how multiple states provided the guidelines for the return of school in the 2021 academic year, which gives school districts directives for their reopening. In South Africa, the Ministry of Education provided regulations on learners' attendance, timetable models, social distancing measures, to name a few. The challenge faced by pre-service teachers in this period is that they are not equipped with a methodology to navigate the classroom in dealing with the psyche, anxiety, technological and social aspects of learners concerned with a health crisis as COVID-19. Lepp et al. (2021) asserts that COVID-19 propelled reorganised learning settings within the education domain and that the stakeholders in school were forced into a new circumstance. As such, pre-service teachers were not exempted from these changes, although the same model of teaching practice was still adopted with no adjustment to suit the COVID 19 prescriptions and regulations. Pre-service teachers' strengths include a tendency to inquire, pay attention, build rapport with children, and increase their social awareness (Harding \& Hbaci, 2015).

According to the Revised Policy on Minimum Requirements for the Teaching Qualification South African (RSA [Republic of South Africa], 2015), an activity where student teachers are placed in schools in order to gain teaching experience is referred to as teaching practice. A qualification therein attests that an organised and logical programme of learning was followed and completed through formal or informal learning provided by institutions of higher learning such 
Tsotetsi, C.T. \& Mile, S.A. Mentor-Mentee Experiences Amidst COVID-19: A Teaching Practice Case Study

as universities, universities of technology and teacher colleges that are recognised. Clarke, Triggs and Nielsen (2014) further stress that a pre-service teacher mentorship programme which takes the form of teaching practice in the South African context and its supplementary practical can be regarded as an induction course that provides support to ascertain that preservice teachers are drawing out to the maximum from the available learning opportunities. Mokoena (2017) deduces that teaching practice is a period where student teachers observe teachers who are already practising in the field in order to learn about teaching skills and classroom management techniques. It is important to note that a student may not be graduated if they do not undergo teaching practice experience in South Africa. This implied that Education students across South African institutions still had to go for their teaching practice during COVID-19.

Kiggundu and Nayimuli (2009) suggest that teaching practice can be the make or break phase for pre-service teachers, maintaining that pre-service teachers can either have a positive or a negative experience during the teaching practice tenure. This period can be challenging and yet an important part of teacher training, drawing into the South African context as a developing country where the belief that the effectiveness of the teaching practice can be diminished or eroded by an array of trials, such as geographical distance, poor and uneven levels of teacher expertise, extensive lack of resources as well as a lack of discipline among a wide cross-section of learners and educators. Moreover, should such challenges not be addressed, they may potentially affect the pre-service teacher's performance during this induction period and, in the long run, alter their perception of the teaching profession in its entirety. Ryan (2016) therefore, concludes that a teaching practice programme displays an interdependent relationship between primary stakeholders, which are the mentors and mentees. In that regard, he asserts that adequate and effective communication between the stakeholders mentioned above can influence the turnout of the induction programme. Communication can thus enhance the practical experience for a pre-service teacher, and lack of thereof can similarly propel a deterioration in performance and in the long run, develop an overall dislike for the profession. Finally, the Educational System blog (2013) emphasises that pre-service teaching programmes are mainly aimed at providing support to enhance teacher learning and to instil in pre-serving teachers a greater degree of self-confidence. These teachers extract a great deal of knowledge from their practice and the school culture settings where they have been placed. Moreover, studies have revealed that a mentor or a supervisor significantly influences the student teacher's performance during teaching practice (Kiggundu, 2007). One can then conclude that pre-service teacher training can be enhanced by a wellplanned mentorship programme that is aimed at providing support and equipping pre-service teachers with expertise to excel in the teaching profession.

Mckingley (2017) describes mentor teachers as professional teachers who are veteran teachers, equally experienced and knowledgeable in their learning area of expertise and also in the school setting contexts. Mentors are responsible for scaffolding pre-service teachers through methodology and professional proficiency (Heeralal \& Bayaga, 2011). Therefore, one can conclude that mentorship stakes a significant role in shaping the value orientations of preservice teachers as they internalise professional expertise, including learner discipline and pedagogical methodologies. In this accord, the quality of teaching practice reflects individual 
Tsotetsi, C.T. \& Mile, S.A. Mentor-Mentee Experiences Amidst COVID-19: A Teaching Practice Case Study

values, perceptions, and experiences (Sternberg, 2008; Grewal et al., 2019). As such, teacher mentorship must not be limited to academic obligation and must extend beyond the teaching and learning dimension. Induction and mentorship programmes positively impact. Little and Nelson (1990) are of the view that mentorship is beneficial to both parties involved- mentors and mentees in a sense that mentorship programmes are essential in asserting inexperienced teachers with a strong induction and start into the teaching career. Equally, veteran teachers get a chance to self-develop and learn in the process. Koki (1997) shared these sentiments and emphasised that supporting student teachers at the onset is important in preserving new teachers in the education system. Formalising the mentor role for experienced teachers also builds another niche in the career ladder for teachers and contributes to educational professionalism (Moody, 2020).

The US Department of Education (2015) denotes the importance of mentoring in preparing pre-service teachers for the demands of a highly enhanced profession Mentor teachers are tasked with training beginning teachers in various aspects of teaching, including instruction and professional etiquette. They provide induction in the implementation of evidence-based instruction and lesson planning and nurture them in that regard. Teaming up student teachers with skilled expert teachers who can mentor them allows them to extend their understanding of teaching theories and approaches and methodologies, classroom management, and prescribed educational system policies through discussions and reflection with their mentor. This teaching practice experience and student learning through a developmental and formative relationship support new teachers in the field (US Department of Education, 2015).

An ultimate aspect that affects the mentor-mentee relationship is the uniqueness of the mentor teacher. There are striking differences in how mentor teachers apprehend and carry out their work with student teachers (Feiman-Nemser \& Parker, 1993). Haddad and Oplatka (2009) maintain that the differences in mentors' perceptions and practices are linked to variances in role expectations, working conditions, programme orientations, and mentor's eagerness to fully partake in the teaching practice experience, support the pre-service teacher and know how well prepared they are for the programme. In the South African context, Du Plessis (2013) notes that the biggest challenge facing the teacher training programmes is poor school management, lack of timetables and teacher position gaps, which means that some student teachers will go to a school and assume the role of teachers as replacements to vacant positions, thus depriving such students an opportunity to learn from someone who is an expert in the field. Du Plessis (2013) also notes that some schools are willing to accommodate students; however, some mentor teachers are not entirely committed to the programme, which results in a zero mentorship impact.

In light of the discussion above, it is important to highlight that both mentor teachers and preservice teachers encounter many curricular and extra-curricular challenges during the teaching practice experience. Therefore, this paper aims to explore the challenges undergone by both parties during the induction of pre-services teachers during the COVID-19 period. Unfortunately, there is a dearth of literature with a focus on mentor-mentee experiences amidst COVID-19. 
Tsotetsi, C.T. \& Mile, S.A. Mentor-Mentee Experiences Amidst COVID-19: A Teaching Practice Case Study

\section{Research Questions}

We structured questions as follows:

The main research question: What are the experiences of mentor and pre-service teachers during the COVID-19 pandemic? The two sub-questions below assisted in responding to the main question.

What are the challenges faced by both the mentors and mentees during this period?

What are the possible solutions to the challenges denoted herewith?

\section{Theorising through Realist Social Theory}

This paper adopted the realist social theory as a lens through which it was conducted. This theory was conceptualised by Margaret S. Archer (1995) and is central to the human constitution, although not limited to that. Therefore, it is important to highlight that this theoretical framework is multi-dimensional and engages an array of theories that can be dissected as separate entities denoted as morphogenetics in this context (Archer, 1995). Archer (2002) supports this notion by alluding to the realist social theory as a theoretical framework that employs the morphogenetic approach theories that speak to the stratified nature of social reality, giving the researcher a multifaceted opportunity to come about with theories that will instigate change. Furthermore, social interactions can be multidisciplinary; therefore, this framework can cut across various social disciplines. Carter and Sealey (2002) assert how they view sociolinguistics as an epitome of human behaviour prescribed by their social actions as in Archer's (1995) ideology, wherein she outlines that society's existence relies on our activities. She also highlights that society is transformable and has no preferred state and we as humans are also immutable as our actions are informed by the society in which we exist. Essentially, realism in this regard is upheld as asserting the nature of things, that is to say, 'the way things are'. Lawson (1996) equally outlines that social theory is overtly steadfast in explaining the nature of social beings and how we access society, particularly referring to the economics discipline.

The social dimension in this regard speaks to the structuration of entities (human constitution as mentioned) and their ability to practise agency (Archer, 2002). This, maintains Archer's theory that people are often 'structured' and this autonomy can favour one structure over the other. Carter and Sealey (2002), whose paper is linguistic inclined, adopt this theoretical framework as a relevant lens to linguistic proficiency. They impute that certain social actions are contextual conditions owed to the structuration of certain entities. Moreover, they argue that structuration is subliminal in approach, and its aftermath is social relations dictated by it, and in turn, social reality turns out to be beyond the awareness and control of the individual. Therefore, it is of utmost significance to outline that humans, in essence, are the only social actors, who in realism, are subject to structured social relations. In that regard, they can practice agency against systematic structures such as religion, politics to name a few (Carter \& Sealey, 2002). The social actors' ability to employ autonomy in their actions is thus not determined by themselves but influenced by other factors. This is further endorsed by Carter and New (2004), who believe that individuals as 'agents and actors' are influenced, though not determined, by their structural situations. 
Tsotetsi, C.T. \& Mile, S.A. Mentor-Mentee Experiences Amidst COVID-19: A Teaching Practice Case Study

The preceding argument of structuration and agency paves the way for Archer's (1995) theory of dualism between two entities. In this theory, she argues that two aspects naturally co-exist in social contexts through social interactions and are interdependent; however, she contends that since they directly influence each other and how the other turns out, one can essentially be existent without the other. Two objects or aspects are said to be related if neither is constituted by the relationship in which each stands to the other. Bread and butter, coffee and milk, a barking dog and a postman, provide examples. In contrast, two objects are said to be internally related if they are what they are and do what they do by virtue of the relationship in which they stand to one other. Landlord and tenant, employer and employee, teacher and student are examples that spring easily to mind. In each case, it is impossible to have the one without the other; each, in part, is what it is and does what it does by virtue of the relation in which it stands to the other (Lawson, 1996).

Our paper employed this theory as it deals with social interactions between human constitutions as prescribed by Archer (1995). Moreover, it focused on two separate entities that can exist independently and in dualism - the mentor and pre-service teacher, as Lawson (1996) exemplified. Although, Carter and Sealey (2002) allude to the subliminal nature of structuration, this is actually true for the two entities which underlie our paper. Pre-service teachers and practising experienced teachers were two primary social actors for this paper but have a wide stratification of social actors who are influential in how they conduct the teaching practice. From big authoritative social players such as politicians and curriculum developers to the learners whose behaviour and sociological and psychological factors determine the efficacy of teaching practice, induction process of pre-service teachers and mentorship.

Carter and New (2004) maintain that two entities can have an agency that is influenced by structural situations. Fundamentally, Mentor teachers can have autonomy or agency in their organisation and principles through which they wish to instil in their students (pre-service teachers); however, its existence is determined and dependent on the need for student teachers. Student teachers who are equally products of institutions of higher learning, governed by both government and institutional policies and coming with their own theoretical ideologies as provided within their pedagogical discourses. This is to say that structuration, agency and dualism are not linear and plainly black and white but do have areas shaded in grey and are influenced by multilayers of structures. Likewise, pre-service teachers can emanate independently with their ideologies and organisation but can actually transform on the influence of the other structures, that is, mentoring. This speaks hereof to Lawson's (1996) theory of dualism that entities can stand separately but are somewhat intertwined in non-linear but rather stratified systems. Therefore, this paper resonates entirely with this theory as it aims at determining two structures firstly as separate entities and their ability to employ agency and then scrutinise them in dualism, as to which one influences or impacts in one way or the other as alluded in Archer's (1995) theory.

\section{Methods}

\section{Design}

Qualitative research donates to the indulgence of the human condition in multifaceted settings and an observed situation (Bengtsson, 2016). This essentially feeds off from the intepretvist 
Tsotetsi, C.T. \& Mile, S.A. Mentor-Mentee Experiences Amidst COVID-19: A Teaching Practice Case Study

paradigm wherein it can be denoted as implying that qualitative research is concerned with unearthing the humanistic circumstance through the perspective of the human in question. Our paper thereof seeks to understand the perspectives of two parties involved in the mentoring process of pre-service teachers. Therefore it relates to qualitative research which is not interested in the figures but the understanding of the realities experienced by the aforesaid groups which can be expressed in words as highlighted by Bengtsson (2016). The case study research design was suitable in this respect, related by Harrison et al. (2017) as dating as far back as recorded history can prove which sociologists and anthropologists used to investigate people's lives and experiences and their understanding of the social and cultural contexts within their world in order to understand the different individual perspectives and ascribed meaning to their world. Such is still the case in current contexts. A case study research can equally unfold through interviews or in researchers observing a certain social group to understand their world. This form of inquiry is entirely relevant to this paper as it aims to understand individuals pre-service and mentor teachers within the spaces they exist.

\section{Sampling}

This paper was couched by purposeful sampling; which refers to individuals who possess the ability to respond to a question within a specific field of specialisation (Koerber \& McMichael, 2008). Our paper's focus is on the two groups of participants. The participants were chosen based on their field experience, especially in the case of mentor teachers, while pre-service teachers were chosen according to their year of study (preferable final year students) who have been exposed to teaching practice previously. The limitation, however, to this sampling method is that in current contexts, the world is hit by a pandemic (COVID-19) which prohibits face-toface contact between individuals or, in cases where they can be in contact, maintain a 1.5 metres social distance. Rationally, research cannot be conducted in such unfavourable circumstances mainly because the respondents' anonymity must be upheld in all regards. Therefore, contact samplings were done through social media platforms like WhatsApp, through recorded audio notes transcribed and in other instances, phone call conversations.

Table 1. Demographics of the participants.

\begin{tabular}{|l|l|l|l|l|}
\hline Participants & Age & Gender & $\begin{array}{l}\text { Year of Study/ } \\
\text { Work wxperience }\end{array}$ & Method of selecting participants \\
\hline $\begin{array}{l}\text { Pre-Service } \\
\text { Teacher 1 }\end{array}$ & $20-25$ & Male & $4^{\text {th }}$ Year & Purposeful participant selection \\
\hline $\begin{array}{l}\text { Pre-service } \\
\text { teacher } 2\end{array}$ & $20-25$ & Female & $4^{\text {th }}$ year & Purposeful participant selection \\
\hline $\begin{array}{l}\text { Mentor } \\
\text { Teacher 1 }\end{array}$ & $25-30$ & Female & 3 years & Purposeful participant selection \\
\hline $\begin{array}{l}\text { Mentor } \\
\text { Teacher } 2\end{array}$ & $25-35$ & Male & 7 years & Purposeful participant selection \\
\hline
\end{tabular}

\section{Data Collection and Instrumentation}

According to Bar-llan (2001), data collection is the most significant aspect of each study, alluding to how great care should be taken into cognizance when it is carried out given that it carries the entirety of the study. Bar-Ilan further (2001) interjects that the internet changes 
Tsotetsi, C.T. \& Mile, S.A. Mentor-Mentee Experiences Amidst COVID-19: A Teaching Practice Case Study

continually; therefore, any paper's discoveries are valid and relevant in the time frame in which the study was conducted. The findings thereof depend a great deal on selecting the data collection tool the author opts for, which the researcher has no control over. It is fundamental to note that selecting a data collection tool is significant in guiding the paper to attaining maximum results which address the research question central to the paper.

Participants for this research were selected at random senior and FET phase schools around the Maluti a Phofung rural in the Eastern Free State, South Africa. In addition, two mentors and two pre-service teachers were selected from a school based on experience in mentor teachers, and current undertaking in a pre-service teacher who is on practicals or who has previously been exposed to teaching practice (particularly because of the COVID-19 pandemic which changed the implementation of the continuation of teaching practice). The participants were interviewed telephonically, upon which their responses were tape-recorded and transcribed for analysis.

The data for this paper was collected using semi-structured interviews. Petrescu, Lazar, Cioban and Doroftei (2017) explain semi-structured interviews as a process of eliciting information by the researcher from the participant by asking questions in a verbal interchange. We used semistructured interviews through social media platforms. Furthermore, the advantage of this type of interchange allows for interviews to provide broad and open responses to questions instead of yes and no replies. Therefore, the most vital point in this accord is for the researcher to choose a participant who is relevant to their area of study in order to elicit as much meaningful information as possible. Smyth (2019) refers to semi-structured interviews as interview questions that are more open-ended in their approach.

\section{Data Analysis}

Our data were analysed through thematic analysis, which refers to a method of analysing qualitative data that can come in the form of interview transcripts. In this method, the recurrent and synonymous themes were examined to identify their commonalities (Caulfield, 2020). Thematic analysis is an excellent approach to research where one is trying to find out something about people's views, opinions, knowledge, experiences or values from a set of qualitative data (Caulfield, 2020). In this method of data analysis, the researcher is concerned with the close examination of the data collected in order to arrange themes or in accordance to their commonalities in order to conclude.

Caufield (2020) notes the various approaches to conducting thematic analysis, which can be arranged in a six-step process; familiarisation denotes getting familiar with the data and knowing what is entailed in the data holistically, which can take form in the transcription of the audio data collected. The second step will be coding which denotes highlighting sections of our text, usually phrases or sentences and coming up with shorthand labels to describe their content. The third is the generating of themes which denotes looking at the labels created, then identifying similarities amongst them then begin thematising them to broader, specific concepts. Reviewing themes denotes making sure that the themes created are useful and correlate with the data collected; the themes must be accurate representations of the data when comparing themes to it. Next, the themes have to be defined and named. Defining 
Tsotetsi, C.T. \& Mile, S.A. Mentor-Mentee Experiences Amidst COVID-19: A Teaching Practice Case Study

themes involves formulating exactly what we mean by each theme, figuring out how it helps us understand the data, and finally writing up these themes.

\section{Trustworthiness and crystallization of Data}

The data validation and reliability were assessed through member checking, wherein transcribed results were returned to participants to ensure accuracy and whether the information resonates with their responses (Birt et al., 2016). On the other hand, in order to reach data crystallization, we got data by reviewing the literature as well as interviewing mentor teachers and mentees. Tracy (2010) urges researchers to use multiple methods of data generation to reach crystallization in qualitative research approaches.

\section{Ethical Considerations}

The participants were allowed to withdraw from the study should they feel uncomfortable, and their identities were withheld and upheld with the utmost confidentiality. Furthermore, participants were given an informed consent form to sign so as to give assurance that their participation is voluntary. Throughout the interviews, we maintained professional standards for managing and conducting research and equally obtained voluntary informed re-consent for any additional data collection at a later stage. We also obtained approval from the Faculty of Education at the University of the Free State and adhered to their ethical standards and procedures for data collection

\section{Results and Discussion}

In this section, the results are presented according to the two sub-questions below,

-What are the challenges faced by both the mentors and mentees during this period?

-What are the possible solutions to the challenges denoted herewith?

Pre-Service Teachers noted as (P-ST1 and P-ST2) and Mentor Teachers noted as (MT1 and MT2).

\section{Challenges Encountered by Mentor Teachers and Pre-service Teachers during Teaching Practice Amidst COVID-19}

\section{Adaptation to school culture/environment}

Adaptation to the school setting can refer to the ability of the student teacher to adapt fully into the school environment, be at par with the organisational culture and have the ability to be socially at ease in the workspace. Deed et al. (2019) opined that teachers must have the ability to adapt to changing settings within the school scope, especially because it is a contemporarily flexible space. Hellsten et al. (2009) premise that the inability of the preservice teachers to adapt to the school setting can ultimately bring about feelings of inadequacy and isolation within the new space. They are often overloaded and overwhelmed by the demands of the profession and, in turn, become frustrated.

PST1: Sometimes, I was unable to manage my time very well. I was going to the class having prepared for a one-hour lesson. When I get there, the content gets prolonged; some students don't understand because they missed most of the content last year due to COVID-19. 
Tsotetsi, C.T. \& Mile, S.A. Mentor-Mentee Experiences Amidst COVID-19: A Teaching Practice Case Study

P-ST2: No, we were not involved in staff meetings, even extra-curricular activities. It was just chess, which the learners asked me to assist them. I was not given that task officially.

The concerns expressed by both participants are evidence that pre-service teachers struggled with the adaptation to the school environment due to the conditions enforced by COVID-19, especially on issues that relate to classroom discourses. Many people have looked up at teachers with beaming awe and high regards, strongly believing in them, and placed their confidence in them, assuming that they would find the ways and means to reach out to students amidst difficulties and go through the rigours to reach out to students effectively (Patimo \& Lucero, 2021). The current methods used in the training of pre-service teachers thus fail to cater to the need for pre-service social inclusivity, especially as schools are flexible environments dictated by the circumstances of the period. In the first case, time management struggle reveals the need for the mentor teacher to provide guidance, particularly because of the transition from institutions of higher learning to schools in COVID-19 conditions, the participant is overwhelmed. In the second statement, the student expresses feelings of inadequacy, at which learners do not recognise him as a 'real' teacher. Härkönen (2013) (as cited in Samuseviča, 2013) denotes that pre-service teachers' professional development and adaptation are highly governed by numerous partial and impartial factors that affect their work.

\section{Support from role players}

The role players who are involved in the induction process of pre-service teachers are firstly the Institution of Educator Training, the Department of Basic Education (hereafter DoE), the principal and the SMT, the mentor teacher and the pre-service teacher. All the parties mentioned above have a role to undertake during the induction process and should extend a hand of support to pre-service teachers in order to ensure that their confidence does not deplete. Lattore-Cosculluela et al.(2021) assert that creativity and collaboration are competencies that aid in the learning in non-conventional classroom environments and can prove effective in developing skills in students. The support from all the parties involved can translate to mutual learning and knowledge transfer. Mutual learning therein means that all role players are engaged in constant interactions through dialogue and develop an understanding which affects a workable atmosphere where reflection, feedback and interpersonal ties are upheld (Salinitri, 2005).

P-ST1: There's no support. There's no support because if you find that your mentor is a new teacher, both of you will just be going around with no guidance, getting to know the content, the implementation and teaching strategies.

P-ST2: I only saw the SMT on the first day; I saw the principal two days before I started. On the day I arrived, I met the principal, he handed me over to the HOD (Head of Department), and the HOD gave me a teacher- a mentor teacher, and that was it.

MT1: So far, I haven't experienced any involvement of body beyond the school environment, either the university where the student comes from or the department.

MT2: The involvement only comes in during the evaluation part. That's where the institution gets involved, but beyond that, I haven't experienced any extended involvement. 
Tsotetsi, C.T. \& Mile, S.A. Mentor-Mentee Experiences Amidst COVID-19: A Teaching Practice Case Study

The repetition of the lack of support from the role players simply denotes the severity of the feeling of the solitude felt by the pre-service teacher. It is evident that pre-service teachers do not receive scaffolding of any sort from the aforementioned role players. Needless to say, this leaves the pre-service teachers with feelings of neglect and takes away from the intended purpose of teaching practice which leaves the pre-service teacher with misconceptions of what teaching practice is about. Equally important, the mentor teacher also expresses the limited involvement from both the Department of Education and the teacher training institutions. The Department of Education can assign teaching practice practitioners to ensure that schools are not maltreating training teachers. Moreover, one can conclude that both the SMT and the principal can employ a more hands-on role than overseers by ensuring that the trainee student is well accommodated, not just by the mentor but by the whole staff members. Laker et al. (2008) hold the view that pre-service teachers predominantly esteemed direct professional support and guidance not only from their mentor teachers, they also valued the communal support of their pre-service and teacher colleagues. The Institution of Educator Training must equally show extensive support to the student teachers as they have expressed feelings of neglect, upon which an appointee from the institution will only come upon observations. The delegates from institutions must do regular check-ups on students.

\section{Mentor teacher awareness}

In this paper, this concept speaks to the knowledge of the mentor teachers about the duties that are expected of them during the induction process. Mentor teacher's insufficient comprehension of promoting pre-service teacher reflection and the pre-service teachers' independence results in less mentorship effect, if not none at all. Jones (2009) alludes that performing the part of a role model and having the authority to be critical and act as a 'friend' at most is challenging, and thus, there should be a critical examining of issues in relation to the control of power which comes with the position of being a mentor. Teachers should be oriented to move away from the shared understanding of what mentorship is about, which is regarded as traditional where there is a linear routine.

P-ST2: On the first day, I found that my mentor teacher was going to a first period. So when I was handed over to him, it was already his first period, which means that I just went with him and observed without him explaining anything to me. And for the next few days, I would just tag along to observe what he does.

MT1: No, there was no formal notice, I only learnt about the arrival at school that morning and the principal told me that we have a visitor and she's coming here to do practicals with no formal warning.

This conversation shows that the mentor teachers lack the knowledge orientations that are supposed to be passed on to the trainee pre-service teachers. From the above conversation, it appears the COVID-19 pandemic resulted in some mentor teachers not being prepared to accommodate students especially alluding to the fact that the second pre-service teacher went to class with his mentor who had not sat down with him prior about anything, the concepts that were to be discussed on the day, among others. Mentor Teacher 1's response is an indication that schools do not formally sit and plan in anticipation of pre-service teachers. Planning about aspects such as the number of student teachers, the teachers that will 
Tsotetsi, C.T. \& Mile, S.A. Mentor-Mentee Experiences Amidst COVID-19: A Teaching Practice Case Study

undertake mentoring duties and how they will be accommodated are not discussed. Childre and Van Rie (2015) assert how hybrid mentor teacher training is optimal in endorsing mentor teacher awareness as mentor teachers face the challenge of not knowing what to do during the training programme. It is evident that schools do not treat teaching practice with the level of seriousness it deserves. This therein indicates that mentor teachers are rather the link that has been neglected within the whole process, having not been oriented on how to accommodate trainees within their scope of work and the likes. Mentor teachers must undergo training on how to provide essential guidance.

\section{Lack of motivation}

This aspect is the lack of motivation on the parts of both mentor and student teachers alike. The confidence in pre-service teachers to recognise themselves as belonging to the space and having a meaningful contribution in the teaching and learning discourses is somewhat limited. More than that, some mentor teachers are disengaged and are not willing to take up the part of mentoring the pre-service teachers.

PST2: It was classroom management... you will find students walking out of the classroom because you are a student teacher. Uh they don't care, they don't ask, they just walk out. They walk out in twos, in pairs to the toilet and the period after break.

MT1: Yes, it's a very big challenge, but because we came from that very same environment where we had to go to schools without warning schools, we have to give room to those student teachers.

MT2: I think it would be a good strategy to encourage mentor teachers. It's a lot of work; it needs a little bit of incentive just to motivate you...

The statement from P-ST2 is evidence that the student teacher also has feelings of inadequacy. Allowing students to walk out without stopping them shows that the pre-service teacher also lacks confidence in his abilities to bring about order to the classroom by putting an end to learner indiscipline. Therefore, this reduces the student teacher's motivation to perform certain tasks and fulfil the demands of the induction process. MT1 speaks of how challenging it is to have the task of scaffolding a pre-service teacher; however, there is little enthusiasm to address these challenges, meaning the motivation to create environments suitable for them to carry their work effectively is depleted; hence they conform and succumb to the tradition of the system. It is important for mentor programme overseers in schools such as principals and SMT's to provide approaches to reinforce pre-service teachers' and mentor teachers' principles and maintain their motivation (He, 2009). For mentor teachers, motivation can be enhanced through offering incentives upon taking up the mentorship role. For pre-service teachers, motivation can be elevated by allowing them to engage in every space within the school curricular and including them in important school functionalities.

\section{Programme on the induction of pre-service teachers}

Pre-service teachers felt that there was no formal programme guiding them at school. Mentors guided pre-service teachers as they deemed fit. This is confirmed by the two pre-service teaches utterances below: 
Tsotetsi, C.T. \& Mile, S.A. Mentor-Mentee Experiences Amidst COVID-19: A Teaching Practice Case Study

P-ST2: The trails are a logbook where you sign; those are for the institution and the file, which is a report back. But if you were to go back to the school, you won't find any document that would indicate my presence in the school for teaching practice on a specific date.

P-ST1: There were no programmes that indicate how teaching practice should unfold. I think the only document that can essentially trace me to the school would be the COVID- 19 screening tool, which I had to fill every morning after my temperature was taken

This conversation reveals no formalised or standardised programme that outlines each role player's expectations within the duration of teaching practice. This, therefore, implies that all the parties involved perform the induction processes differently. The lack of a universal teaching practice programme eliminates the standardisation pertaining to which aspects of both pedagogical discourses and the overall school culture should be heightened. As such, each individual teacher transfers whatever knowledge they deem important to the student, but not the knowledge that can ascertain good, quality teachers. In turn, pre-service teachers end up internalising and copying the modus operandi of the mentor teacher in different situations, not what is outlined in the policies. In some instances, some pre-service teachers end up exiting the teaching practice period without having learnt anything valuable due to the fact that teachers operate differently, and while one teacher might approach teaching practice with enthusiasm, another one might not. Therefore, it is logical to assume that a programme will assist in ensuring that pre-service teachers deduce as much as possible from the programme as they will be inquiry filled if they have a guiding tool of which features they ought to enquire. According to Ingersoll (2012), teacher training programmes are a vital tool in the induction of pre-service teachers as they serve as a guideline on what the process should entail. On the other hand, Tsotetsi et al. (2020) believe that the quality of induction of pre-service teachers can affect the quality of teaching and learning offered in schools.

\section{Solutions to the Challenges Faced by Pre-service Teachers and Mentor Teachers}

\section{Multiplicity in mentorship}

Mentorship multiplicity in this regard refers to pre-service teachers receiving mentorship not only from a single mentor teacher but from multiple teachers in the school who are in the capacity to provide such. Collaborative teaching must be encouraged in order to ensure that that pre-service teachers get the best out of the mentorship programme.

MT2: I believe it is our responsibility as teachers in the school to teach student teachers about the profession, especially as we come from the same system, by showing them how things are done, supervising them, assessing them, engaging them also in collaboration teaching.

MT1: Of course, I'm the mentor teacher, but sometimes, it becomes a little too much. I think some help from the SMT would do.

My colleagues are quite helpful. For example, on the days I'm absent, I'm not feeling well, or I'm not able to make it to work, I'd have my colleagues taking over in mentoring my students and guiding them in my absence. 
Tsotetsi, C.T. \& Mile, S.A. Mentor-Mentee Experiences Amidst COVID-19: A Teaching Practice Case Study

The conversation revealed that multiple mentorships could assist not only the student teacher to draw the maximum out of the teaching practice experience, but it can be beneficial to the mentor teacher in cases where they have other obligations that may cause them to be absent from work. MT2 speaks of collaborative teaching, which is essential in imparting multiple teacher orientations to a student. This implies that if the pre-service teacher is not only restricted to one mentor, they internalise as much work and professional etiquette from all the teachers who act in their mentor capacity. This also reveals that in the absence of the mentor teacher, the inductee teacher is not obliged to act in the teacher capacity to close the teacher's position gap, as they can be redirected to another availably assigned mentor teacher. Dlamini (2017) divulges the importance of collaborations in preparing pre-service teachers for the world of work, which can eliminate misconceptions regarding the occupation and affect their efficacy.

\section{Mentor teacher workshops}

Mentor teacher workshops in this regard refer to the training of mentor teachers before they accommodate pre-service teachers in their practice. Mainly because teachers receive no formal help from designated authorities or mentors receive no formal guidance from their district departments, and when they are tasked to perform such a duty, they struggle.

MT1: I think the heads of departments in higher education institutions like the UFS, the people who are handling this programme of student teachers, are supposed to have workshops, some kind of workshops with the schools around. They are supposed to have that workshop where they emphasise the points that the mentor teachers must prioritise when these student teachers arrive in the school, the time frames ... including conduct, the conduct of the student teacher at the school, how are they supposed to be conducted and how these mentor teachers are supposed to report to the institution, report on the behaviour and level of preparedness of the pre-service teacher.

The conversation reveals the importance of workshops and mentor teacher training. From MT1's response, we can deduce that mentor teachers are stranded when given the mammoth task of inducting pre-service teachers. What is strikingly important is that the participant highlights that teacher training institutions should collaborate to draw up a guiding tool, be it a policy or any form of document that will serve as a guideline on how to conduct the induction. What is essential here is to note that teachers need preparation programmes to show that they can mentor the inductees.

\section{Online pre-service teacher diaries}

As suggested by participants, these online diaries refer to web platforms that allow pre-service teachers an opportunity to record their assessments and their experiences online as they transpire. This is important as it will ensure that it keeps a record of what pre-service teachers encounter during their induction, especially in such a critical time as COVID-19, where the entire school system is forced to move from traditional teaching methods to integrating technology. Pokhrel and Chhetri (2021) denote a lack of online educational infrastructure. However, this is not the case for institutions of higher learning as they are well equipped and have been using online learning for some time. 
Tsotetsi, C.T. \& Mile, S.A. Mentor-Mentee Experiences Amidst COVID-19: A Teaching Practice Case Study

The COVID-19 pandemic forced teachers and educational leaders to reckon with existing digital inequities that some were not even aware existed because distance learning was the main and sometimes only learning platform at the beginning of the COVID-19 lockdown (Williams, McIntosh \& Russell, 2021; Subedi \& Subedi, 2020).

P-ST2: I think the institution should be there holistically, not just come once to assess you. I think if I go back to the solution that I provided, the online part, that is the daily assessment on my part whereby when you come out of the class, you sign in and then send your experience of the classroom for that day so that you send ideas as they come or those experiences as they come. So it will be sort of a diary, an online diary so that you can be assisted immediately. And then the assessment should be done there, and the lecture should be involved in those discussions.

The conversation above reveals the importance of integrating technology into the teaching practice programme. Online diaries can prove helpful by ensuring that teachers' day-to-day encounters are recorded online and are responded to with utmost urgency. What is important is that these online programmes will ensure that there's communication flow between the major stakeholders of the induction programme, being the institution of higher learning and the pre-service teacher. Madlela (2015) outlines how incorporating ICT into teaching practice has altered the domain and brought about positives which allow for the smooth sailing of the programme and eliminate backlogs. Inevitably so, these teacher diaries may have challenges as there are glitches with the use of technology; therefore, the online diaries can prove helpful in ensuring that induction programmes are a success.

\section{Role players' involvement}

This aspect looks at the role each role player employs in the induction process. Literature reveals that principals, teacher training institutions, and the Department of Education are rather invincible in the induction process. As such, mentor teachers find themselves having to carry the whole responsibility of ensuring that pre-service teachers are well trained across the school settings.

MT2: School Management Teams can try to be more involved so that pre-service teachers don't feel overwhelmed by the work, especially in the middle of such a pandemic where sometimes I also do not know how to go about my work, how do I then provide guidance? I think from all the circulars I have seen from the Department, during this time, none has referenced how pre-service teachers should be accommodated in schools.

This aspect speaks to the notion that all the role players involved in the induction process must be held accountable. Essentially they should be the primary the Department of Education as the primary stakeholder should be in position to direct the whole programme to ensure that pre-service teachers and mentor teachers alike are not overwhelmed. As mentioned in the conversation above, the other role players, including the principal, should champion the interests of pre-service teachers through extensive involvement during the induction process as the product of the whole programme ploughs back to the Department of Education. Ntsoane's (2017) paper revealed that SMT members in schools do certainly initiate their preservice teachers. However, their duties and exertions are adversely affected by the lack of an 
Tsotetsi, C.T. \& Mile, S.A. Mentor-Mentee Experiences Amidst COVID-19: A Teaching Practice Case Study

apparent and comprehensible induction policy, further enhanced by the lack of involvement from the Education Department workforce and a lack of training.

\section{Conclusion}

This paper, titled: Mentor-mentee experiences amidst COVID-19, was concerned with the challenges experienced by both mentors and mentees. The challenges that faced both mentor and mentee teachers were dissected to provide practical solutions that aided in solving the problem of poor mentorship programmes, which essentially resulted in zero mentorship impacts. Zero mentorship impacts imply that pre-service teachers draw the least from a programme that was conceptualised to provide an on-the-job learning experience. This, therefore, pushes prompts a dislike for the profession and will eventually result in lesser human capital. Based on the results, a collaborative approach should be employed to deal with some of the challenges experienced by mentors and mentees.

\section{Recommendations}

The Department of Basic Education must be wholly involved in the induction of trainee teachers by employing personnel that will be responsible for doing check-ups on pre-service teachers. The Department must also introduce workshops to train veteran teachers on how to conduct inductions and what aspects they must prioritise during training. They must also hold the responsibility of establishing programmes in collaboration with teacher training institutions that will serve as guidelines on what mentor teachers should do. Institutions of higher learning must also play a proactive role and not only surface towards the end of the programme when pre-service teachers must be evaluated. Institutions must also introduce the use of technology within the programme to answer students at their earliest convenience. Finally, pre-service teachers themselves must take the initiative in their learning experience.

\section{References}

Archer, R. (2018). Education policy and realist social theory: Primary teachers, child-centred philosophy and the new managerialism. London: Routledge.

Bar-llan, J. (2001). Data collection methods on the web for info metric purposes: A review and analysis. Scientometrics, 50, 7-32. https://doi.org/10.1023/A:1005682102768

Beeth, M. E., \& Adadan, E. (2006). The influences of university-based coursework on field experience. Journal of Science Teacher Education, 17(2), 103-120. https://doi.org/10.1007/s10972-006-9013-8

Bengtsson, M. (2016). How to plan and perform a qualitative study using content analysis. Nursing Plus Open, 2, 8-14. https://doi.org/10.1016/i.npls.2016.01.001

Birt, L., Scott, S., Cavers, D., Campbell, C., \& Walter, F. (2016). Member checking: A tool to enhance trustworthiness or merely a nod to validation?. Qualitative Health Research, 26(13), 1802-1811. https://doi.org/10.1177\%2F1049732316654870

Carter, B., \& New, C. (2004). Making realism work: Realist social theory and empirical research. London: Routledge.

Carter, B., \& Sealey, A. (2002). Language, structure and agency: What can realist social theory offer to sociolinguistics?. Journal of Sociolinguistics, 4(1), 3-20.

https://doi.org/10.1111/1467-9481.00100 
Tsotetsi, C.T. \& Mile, S.A. Mentor-Mentee Experiences Amidst COVID-19: A Teaching Practice Case Study

Childre, A.L. and Van Rie, G.L., (2015). Mentor teacher training: A hybrid model to promote partnering in candidate development. Rural Special Education Quarterly, 34(1), https://doi.org/10.1177\%2F875687051503400104

Clarke, A., Triggs, V. \& Nielsen, W. (2014). Cooperating teacher participation in teacher education: A review of the literature. Review of Educational Research, 84(2), 163-202. https://doi.org/10.3102\%2F0034654313499618

Dean, B.A. (2018). The interpretivst and the learner. International Journal of Doctoral Studies, 13, 1-8. https://doi.org/10.28945/3936

Deed, C., Blake, D., Henriksen, J., Mooney, A., Prain, V., Tytler, R., ... \& Fingland, D. (2019). Teacher adaptation to flexible learning environments. Learning Environments Research, 1-13.

Dlamini, M.E. (2017). Preparing student teachers for teaching in rural schools using work integrated learning. Independent Journal of Teaching and Learning, 3(1), 86-96. https://hdl.handle.net/10520/EJC-eeafe5301

Du Plessis, E. (2013). Mentorship challenges in the teaching practice of distance learning students. The Independent Journal of Teaching and Learning, 8(1), 29-43. https://hdl.handle.net/10520/EJC145141

Educational System Blog. (2013). A narration on education: pre-service and in-service training for quality improvement. Available at: < https://educationalsystem.blogspot.com/2012/07/pre-service-and-in-service-training-for.html> (Retrieved on 20 March 2020).

Fantilli, R. D., \& McDougall, D. E. (2009). A study of novice teachers: Challenges and supports in the first years. Teaching and Teacher Education, 25(6), 814-825. https://doi.org/10.1016/j.tate.2009.02.021

Feiman-Nemser, S., \& Parker, M. B. (1993). Mentoring in context: A comparison of two US.programmes for beginning teachers. International Journal of Educational Research, 19,(8): 699-718. https://doi.org/10.1016/0883-0355(93)90010-H

Haddad, D.I. \& Oplatka, I. (2009). Mentoring novice teachers: motives, process, and outcomes from the mentor's point of view. The New Educator, 5, 45-65.

https://doi.org/10.1080/1547688X.2009.10399563

Harding, J. L. \& Hbaci, I. (2015). Evaluating pre-service teachers math teaching experience from different perspectives. Universal Journal of Educational Research, 3(6), 382-389. https://doi.org/doi 10.13189/ujer.2015.030605

Harrison, H., Birks, M., Franklin, R., \& Mills, J. (2017). Case study research: Foundations and methodological orientations. Qualitative and Social Research Forum, 18 (1), 1-17. https://doi.org/10.17169/fqs-18.1.2655

$\mathrm{He}, \mathrm{Y}$. , (2009). Strength-based mentoring in pre-service teacher education: A literature review. Mentoring \& Tutoring: Partnership in Learning, 17(3), 263-275. https://doi.org/10.1080/13611260903050205

Heeralal, J., \& Bayaga, A. (2011). Pre-service teachers' experiences of teaching practice: Case of South African university. Journal of the Social Sciences, 28(2), 99-105. https://doi.org/10.1080/09718923.2011.11892933 
Tsotetsi, C.T. \& Mile, S.A. Mentor-Mentee Experiences Amidst COVID-19: A Teaching Practice Case Study

Hellsten, L. A. M., Prytula, M. P., Ebanks, A., \& Lai, H. (2009). Teacher induction: Exploring beginning teacher mentorship. Canadian Journal of Education/Revue Canadienne de l'éducation, 32(4), 703-733. https://www.jstor.org/stable/canajeducrevucan.32.4.703

Grewal, I., Maher, A., Watters, H., Clemens, D., \& Webb, K. (2019). Rewriting Teacher Education: Food, Love, and Community. Journal of Culture and Values in Education, 2(3), 44-60. https://doi.org/10.46303/jcve.03.02.3

Ingersoll, R.M., (2012). Beginning teacher induction what the data tell us. Phi delta kappan, 93(8), 47-51. https://doi.org/10.1177\%2F003172171209300811

Jones, M. (2009). Supporting the supporters of novice teachers: An analysis of mentors' needs from twelve European countries presented from an English perspective. Research in Comparative and International Education, 4(1), 4-21.

https://doi.org/10.2304\%2Frcie.2009.4.1.4

Kelly, M. (2019). Importance of effective teacher training. ThoughtCo. Available at: < https://www.thoughtco.com/importance-of-effective-teacher-training-8306> (Retrieved on 19 March 2020).

Kiggundu, E. (2007). Teaching practice in the Greater Vaal triangle area: The student teachers' experience. Journal of College Teaching and Learning, 4(6), 25-36. https://doi.org/10.19030/tlc.v4i6.1572

Kiggundu, E.M., \& Nayimuli, S.T. (2009). Teaching practice: A make or break phase for student teachers. South African Journal of Education, 29(3), 345-358. https://doi.org/ https://doi.org/10.15700/saje.v29n3a129

Koerber, A., \& McMichael, L. (2008). Quaitative sampling methods A primer for technical communicators. Journal of Business and Technical Communication, 22, 454-469. https://doi.org/10.1177\%2F1050651908320362

Koki, S. (1997). The role of teacher mentoring in educational reform. Pacific Resources for Education and Learning: Honolulu Hawaii.

Laker, A., Laker, J. C., \& Lea, S. (2008). Sources of support for pre-service teachers during school experience. Mentoring \& Tutoring: Partnership in Learning, 16(2), 125-140. https://doi.org/10.1080/13611260801916234

Latorre-Cosculluela, C., Suárez, C., Quiroga, S., Sobradiel-Sierra, N., Lozano-Blasco, R., \& Rodríguez-Martínez, A. (2021). Flipped classroom model before and during COVID-19: Using technology to develop 21st century skills. Interactive Technology and Smart Education.

Lawson, T. (1996). Developments in Economics as realist social theory.. Review of Social Economy, 54(4), 05-22. https://doi.org/10.1080/00346769600000026

Lepp, L.; Aaviku, T.; Leijen, I.; Pedaste, M.; Saks, K. (2021). Teaching during COVID-19: The decisions made in teaching. Educ. Sci, 11, 47.

https://doi.org/10.3390/educsci11020047

Limbers, A.C. (2020). Factors associated with caregiver preferences for children's return to school during the COVID-19 pandemic. Journal of School Health, 91(1), 3-8.

https://doi.org/10.1111/josh.12971

Little, J. \& Nelson, L. (1990). A leader's guide to mentor training. Far West Laboratory for Educational Research and Development: San Francisco. 
Tsotetsi, C.T. \& Mile, S.A. Mentor-Mentee Experiences Amidst COVID-19: A Teaching Practice Case Study

Madlela, B. (2015). ICT opportunities and threats in implementing teaching practice programmes. Universal Journal of Educational Research, 3(6), 351-358. https://doi.org/10.13189/ujer.2015.03060

McKingley, D. (2017). The importance of mentoring new teachers. INcompassing Education. Available at: < http://incompassinged.com/2017/07/14/the-importance-of-mentoringnew-teachers/ $>$ (Retrieved on 28 February 2020.)

Mokoena, S. (2017). Student teachers' experiences of teaching practice at open and distance learning institutions in South Africa. Turkish Online Journal of Distance Education, 18(2), 122-133. https://doi.org/10.17718/tojde.306564

Moody, R. (2020). Contextualizing "Practice": Helping Pre-Service Teachers Unpack the Ideological and Sociopolitical Dimensions of Required Practices for Licensure. Journal of Curriculum Studies Research, 2(2), 60-80. https://doi.org/10.46303/jcsr.2020.10

Nancy, L. (2007). Critical thinking dispositions as an outcome of undergraduate education. The Journal of General Education, 56(1), 17-33. https://doi.org/10.1080/00393541.2006.11650083

Ntsoane, L.D., (2017). The role of School Management Team members in the induction of novice teachers in rural schools. Doctoral dissertation, University of Pretoria.

Patimo, D.M. \& Lucero, M. B. A. (2021). Predictors of Success in Advance Higher Education: A Case in Northwest Samar State University, Philippines. Research in Social Sciences and Technology, 6 (1), 40-52. https://doi.org/10.46303/ressat.2021.3

Pokhrel, S., \& Chhetri, R. (2021). A literature review on impact of covid-19 pandemic on teaching and learning. Higher Education for the Future, 8(1), 133-141. https://doi.org/10.1177/2347631120983481

Petrescu, S.H., Lazar, A., Cioban, C., \& Doroftei, I. (2017). Semi-structured interview. In O. R. Ilovan \& I. Droftei, Qualitative research in regional geography: A methodological approach (pp. 37-51). Romania: Babes-Bolyai University.

Ryan, T. G. (2016). The pre-service educator as an action researcher and leader. Action Researcher in Education, 7, 1-13.

Ryan, T.G., Young, D.C. \& Gauthier, W.L.K. (2017). Action research within pre-service teacher education. Teaching \& Learning Journal, 10(3), 1-18.

Samuseviča, A. Support opportunities for professional development of the novice teacher. Reorientation of teacher education towards sustainability through theory and practice, 141.

Salinitri, G. (2005). The effects of formal mentoring on the retention for first year, low achieving students. Canadian Journal of Education, 28(3), 853-873. https://doi.org/10.2307/4126458

Smyth, D. (2019). The difference between structured and semi-structured interviews. In Qualitative research. Bizfluent. Accessed At: < https://bizfluent.com/info-12050751difference-between-structured-semistructured-interviews-qualitative-research.html> (Retrieved on 26 March 2020).

Subedi, D., \& Subedi, R. (2020). Practicing Self Learning of ICT for Resilience Amidst the COVID-19 Outbreak: Experiences from Kathmandu Valley. Research in Educational Policy and Management, 2(2), 78-96. https://doi.org/10.46303/repam.2020.5 
Tsotetsi, C.T. \& Mile, S.A. Mentor-Mentee Experiences Amidst COVID-19: A Teaching Practice Case Study

(RSA) Republic of South African Government Gazette 38487. (2015). National Qualifications Framework Act (67/2008). Pretoria: Government Printers.

Tarman, B. (2012) Prospective Teachers' Beliefs and Perceptions about Teaching as a Profession, Educational Sciences: Theory \& Practice - 12(3), 1-24.

Tracy, S. J. 2010. Qualitative Quality: Eight "Big - Tent" Criteria for Excellent Qualitative Research. SAGE Publications. [Accessed 01 June 2021] from DOI: 10.1177/1077800410383121.

Tsotetsi, C.T., Omodan, B.I., \& Dube, B. (2020). Decolonising the practical space in rural teacher education: The vehicle of peer assessment. Alternation Journal, 27(2), 151172. https://doi.org/10.29086/2519-5476/2020/v27n2a8

US Department of Education. (2015). Promoting teacher effectiveness: Teacher induction and mentoring brief. Literacy Information and Communication Systems-LINCS: American Institute for Research.

Williams, T.K., McIntosh, R.W., \& Russell, W.B. (2021). Equity in distance education during COVID-19. Research in Social Sciences and Technology, 6(1), 1-24.

https://doi.org/10.46303/ressat.2021.1 